Article

\title{
Dehydration of (Perfluoroalkyl)tetramethylcyclopentenols
}

\section{Jan Čermák ${ }^{1,2, *}$, Thu Huong Nguyen Thi ${ }^{2}$, Jaroslav Včelák ${ }^{1}$ and Alena Krupková ${ }^{1}$}

1 Institute of Chemical Process Fundamentals of AS CR, v.v.i., Rozvojová 135, 16502 Prague 6, Czech Republic; E-Mails: vcelak@icpf.cas.cz (J.V.); krupkova@icpf.cas.cz (A.K.)

2 Department of Chemistry, Faculty of Science, Purkynje University Ústí nad Labem, České mládeže 8, 40096 Ústí nad Labem, Czech Republic; E-Mail: Thu-Huong.Nguyen-Thi@ujep.cz (T.H.N.T.)

* Author to whom correspondence should be addressed; E-Mail: cermak@icpf.cas.cz; Tel.: +420-220-390-356; Fax: +420-220-920-661.

Received: 23 March 2011; in revised form: 4 May 2011 / Accepted: 11 May 2011 /

Published: 17 May 2011

\begin{abstract}
Perfluoroalkyl) tetramethylcyclopentenols (alkyl $=n$-butyl, $n$-hexyl, $n$-octyl) were dehydrated to a complex mixture of endo, endo-(perfluoroalkyl) tetramethylcyclopentadienes and their endo-, exo-isomers. It was found in preliminary screening experiments that the best reagent for this transformation, giving an $89 \%$ yield of isomeric product mixture, was $\mathrm{P}_{2} \mathrm{O}_{5}$ in benzene at $80-90{ }^{\circ} \mathrm{C}$. Products were characterized on the basis of their mass spectra and retention time information, and some peaks in the mass spectra were identified from their molecular fragments. Structures were assigned to the three most abundant products of (perfluorohexyl)tetramethylcyclopentenol dehydration. Formal dehydration kinetics showed a second order reaction in benzene but zeroth order with induction period in chlorobenzene, suggesting mass transfer limitations in the more polar chlorobenzene. Some of the products were formed by consecutive isomerization of the others, as shown by the kinetic analysis.
\end{abstract}

Keywords: dehydration; fluorous cyclopentadienes; cyclopentenols

\section{Introduction}

The current interest in fluorous biphase systems [1] in general and in fluorous biphase catalysis $[1,2-8]$ in particular has led to the introduction nowadays of a broad spectrum of ligands soluble in 
fluorous phases. The synthetic design of fluorous cyclopentadienes, although surprisingly somewhat lagging behind the developments, e.g. in the area of fluorous phosphines [ref. 1, p. 247], brought so far several novel types of cyclopentadienes and cyclopentadienyl complexes made fluorophilic by the attachment of polyfluorinated chains - fluorous ponytails. These include cyclopentadienes with one [9], two [10-12] or more [13,14] (perfluoroalkyl)ethyl chains, cyclopentadienes with silicon atoms directly bonded to the ring to separate electronic effects of the fluorous ponytail [15-18] and cyclopentadienes monosubstituted with perfluoroalkyl chains [9], which are difficult to handle or use for metal complexation. The last of the so far known types of fluorous cyclopentadienes is represented by the (perfluoroalkyl)tetramethylcyclopentadienes prepared in our group [16,19-21]. In the latter compounds the electrondonating effect of four methyl groups compensates for the opposite effect of the perfluoroalkyl chain bonded directly to the ring, providing stable precursors to ligands with electronic properties close to the unsubstituted cyclopentadienyl but steric properties comparable to pentamethylcyclopentadienyl. These ligands may be considered to be higher homologs of the Gassman ligand [22-28].

The two-step synthesis of (perfluoroalkyl) tetramethylcyclopentadienes [19] started with the nucleophilic addition of in situ prepared perfluoroalkyl Grignard reagent on 2,3,4,5-tetramethylcyclopent-2-enone with the isolation of a mixture of perfluoroalkyl tertiary alcohols after aqueous acid workup. This mixture was characterized by GC-MS data only and was then subjected to dehydration with $\mathrm{POCl}_{3}$ /pyridine [29] affording a mixture of (perfluoroalkyl)tetramethylcyclopentadienes and their endo,exo-isomers which were all deprotonable to only one common substituted cyclopentadienyl anion. The reported yield in this second step didn't exceed $71 \%$, an unsatisfactory value in view of the relatively high price of the starting compounds. Therefore, in this work the dehydration step is studied in detail, including the kinetics of formation of the diene isomers.

To our best knowledge, there are no studies dealing with dehydration of perfluoroalkyl substituted tertiary alcohols except for a few dealing with the dehydration of the first members of the homologous series, trifluoromethyl-substituted tertiary alcohols (e.g. [30,31]). Because of the expected destabilizing effect of strongly electron attracting perfluoroalkyl groups on the intermediate carbocation, our work may be of general interest to organic chemists.

\section{Results and Discussion}

\subsection{Screening of Dehydration Agents}

(Perfluoroalkyl)tetramethyl cyclopentenols were described [19] as tertiary alcohols stable at temperatures in the $70-100{ }^{\circ} \mathrm{C}$ range and resistant to dehydration by usual acid catalysis or by treatment with iodine, which are common reagents used to catalyze dehydration of tertiary alcohols. The difficulty of dehydration can be expected in view of the destabilization of intermediate tertiary carbocations by the strongly electron-accepting perfluoroalkyl group. To improve the low reported yield of (perfluoroalkyl)tetramethylcyclopentadienes we first tested several common dehydration agents including modification of the original procedure [19], Lewis acid catalysis, and use of microwave heating. 
The originally used dehydration by $\mathrm{POCl}_{3}$ in pyridine led to partial decomposition resulting in considerable amounts of by-products (Table 1). Modification of the procedure consisting in immediate.

Table 1. Results of screening experiments

\begin{tabular}{ccccc}
\hline Reagent(s) & Solvent & $\begin{array}{c}\text { Temperature } \\
{\left[{ }^{\circ} \mathbf{C} \text { /Time }[\mathbf{h}]\right.}\end{array}$ & $\begin{array}{c}\text { Sum of unreacted } \\
\text { alcohols [\%] }\end{array}$ & Sum of dienes [\%] \\
\hline $\mathrm{POCl}_{3}$ & pyridine & $90 / 4$ & 10 & 59 \\
$\mathrm{BF}_{3} \cdot \mathrm{Et}_{2} \mathrm{O}$ & diethyl ether & $35 / 9$ & 14 & $77^{\mathrm{b}}$ \\
$\mathrm{SOCl}_{2}$ & benzene & $90 / 9$ & 2 & $91^{\mathrm{c}}$ \\
$\mathrm{PCl}_{5} /$ pyridine $^{\mathrm{c}}$ & benzene & $90 / 10$ & 0 & $90^{\mathrm{c}}$ \\
$\mathrm{P}_{2} \mathrm{O}_{5}$ & benzene & $90 / 9$ & 6 & 89 \\
$\mathrm{P}_{2} \mathrm{O}_{5}$ & toluene & $120 / 7^{\mathrm{a}}$ & 5 & 86 \\
$\mathrm{P}_{2} \mathrm{O}_{5} / \mathrm{BF}_{3} \cdot \mathrm{Et}_{2} \mathrm{O}$ & diethyl ether & $42 / 8$ & 14 & 83 \\
$\mathrm{P}_{2} \mathrm{O}_{5} / \mathrm{BF}_{3} \cdot \mathrm{Et}_{2} \mathrm{O}$ & diethyl ether & $25 / 168$ & 10 & 86 \\
\hline \multicolumn{4}{c}{${ }^{\mathrm{a}}$ microwave heating; $^{\mathrm{b}}$ reaction mixture quickly decomposed; ${ }^{\mathrm{c}}$ solid by-products. }
\end{tabular}

Extraction of products from the reaction mixture did not improve the procedure and only $55 \%$ yield of cyclopentadienes was obtained. Higher yield of cyclopentadienes was observed with catalysis by boron trifluoride, however the reaction mixtures gradually turned dark. Higher yields were recorded with thionyl chloride or phosphorus pentachloride in benzene, but a considerable amount of solid, probably polymeric, by-products was observed.

Reflux with phosphorus pentoxide in benzene was found to be the dehydration method of choice giving clear reaction mixtures, the lowest amount of by-products ( $5 \%$ as determined by GC), and only liquid by-products. Furthermore, the workup produced phosphoric acid which was likely more easily washed out from the products than $\mathrm{HCl}$ or $\mathrm{BF}_{3} \cdot \mathrm{Et}_{2} \mathrm{O}$, thus preventing any further decomposition of product mixtures.

Our attempt to use microwave heating to accelerate the reaction in toluene solvent didn't show any distinct improvement; boron trifluoride catalysis in addition to $\mathrm{P}_{2} \mathrm{O}_{5}$ treatment decreased the necessary reaction temperature even to room temperature, but also decreased somewhat the yield of cyclopentadienes. In the series of homologs the rate of reaction, followed by GC analysis of samples taken at regular intervals, changes in a surprising way: perfluorohexyl compounds dehydrate approximately two times faster than perfluorooctyl and perfluorobutyl derivatives, while perfluorobutyl derivatives react slightly slower that perfluorooctyl compounds.

\subsection{Kinetics of Dehydration of (Perfluoroalkyl)tetramethylcyclopentenols with $\mathrm{P}_{2} \mathrm{O}_{5}$}

\subsubsection{Identification of Products}

There are two posible regioisomers for starting (perfluoroalkyl) tetramethylcyclopentenols, three regioisomers of (perfluoroalkyl) tetramethylcyclopentadienes and six regioisomers of their endo,exo-isomers. However, these compounds may contain up to three stereocenters therefore the number of diastereomers with different physical properties is higher. The relatively high number of possible stereoisomeric structures for (perfluoroalkyl)tetramethylcyclopentenols 1-8, (perfluoroalkyl)- 
tetramethylcyclopentadienes 9-11 and their endo,exo-isomers 12-23 explains the high number of individual compounds found by GC/MS (Figures 1 and 2).

Figure 1. Possible structures of (perfluoroalkyl) tetramethylcyclopentenols.
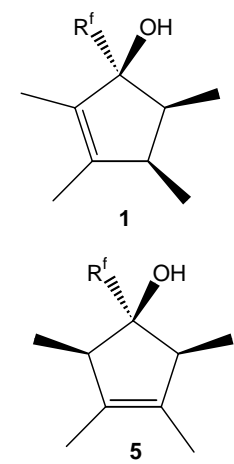

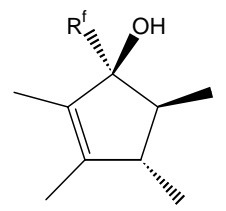

2

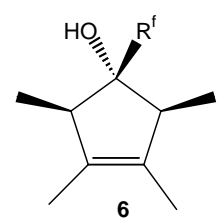

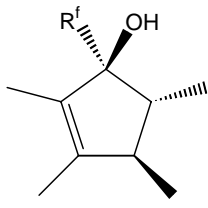

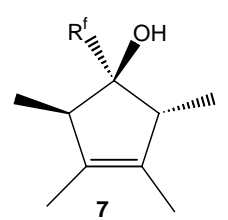

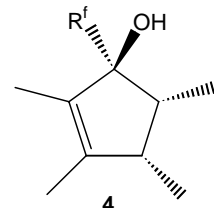

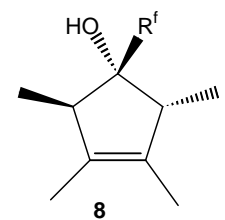

Figure 2. Possible structures of (perfluoroalkyl) tetramethylcyclopentadienes and their endo-, exo-isomers.
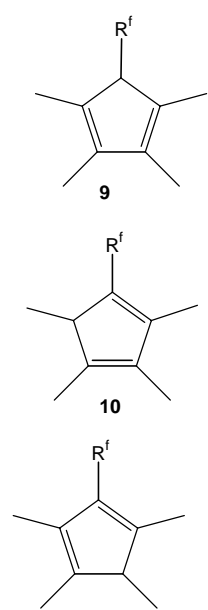
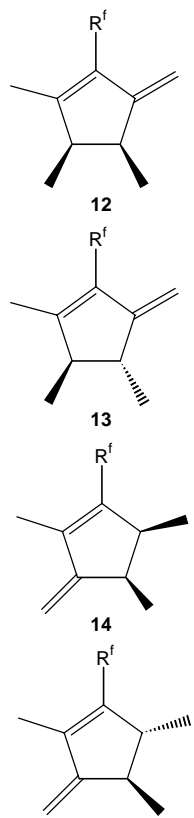

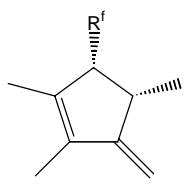

16
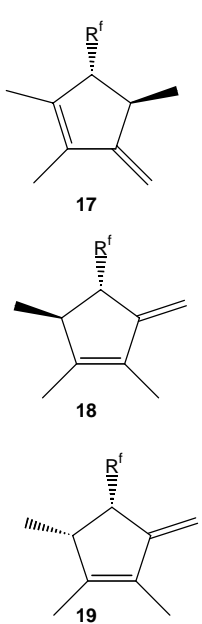
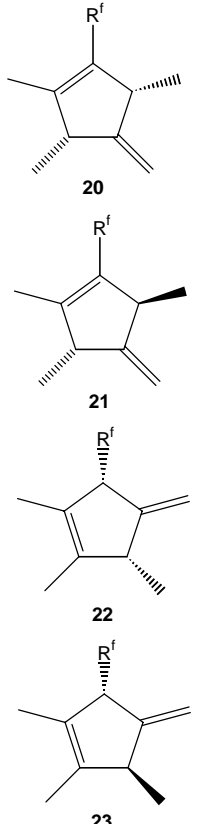

The identification (without generally assigning the structures) of experimentally obtained isomers A-K (dienes) and V-Z (alcohols) was based on both retention times and mass spectra, and is summarized in Tables 2-4 for the three perfluoroalkyl chain lengths. The alcohols exhibited no molecular ions and the peak with the highest mass belonged to a dehydrated fragment. The fragment with $\mathrm{m} / \mathrm{z}=139$ assigned to the tetramethylcyclopentenol ring after perfluorinated chain cleavage was highly characteristic for the alcohols. The dienes showed medium intensity molecular ions which then lost methyls or HF. Both alcohols and dienes contained fragments of $m / z 171,121$, and 69 , assigned to $\left[\mathrm{Me}_{4} \mathrm{C}_{5} \mathrm{HCF}_{2}\right]^{+},\left[\mathrm{Me}_{4} \mathrm{C}_{5} \mathrm{H}\right]^{+}$, and $\left[\mathrm{CF}_{3}\right]^{+}$ions, respectively. We were able to assign only structures of the three most abundant products, namely $\mathbf{A}^{\mathbf{6}}$, which was identified as the regioisomer $\mathbf{1 2} / \mathbf{1 3}, \mathbf{E}^{\mathbf{6}}$ was identified as $\mathbf{9}$, and the main product $\mathbf{G}^{\mathbf{6}}$ was identified as $\mathbf{1 0}$, according to ${ }^{13} \mathrm{C}-\mathrm{NMR}$ spectrum analysis of samples with different proportion of individual products [19]. Interestingly, in the mass pectrum of 
the isomer with exocyclic double bond $\mathbf{A}^{6}$ the ion with $\mathrm{m} / \mathrm{z}=121$ prevails whereas cyclopentadiene isomers $\mathbf{E}^{\mathbf{6}}$ and $\mathbf{G}^{\mathbf{6}}$ have $\mathrm{m} / \mathrm{z}=171$ as the basic ion. The ratio between the occurrence of ions of $\mathrm{m} / \mathrm{z}$ 121 and 171 thus seems to define the type of product, either an endo,exo diene isomer or an endo,endo one.

Table 2. Composition of reaction mixture of perfluorobutyl derivatives ${ }^{\text {a }}$.

\begin{tabular}{|c|c|c|c|c|c|c|c|}
\hline \multirow[b]{2}{*}{ Isomer } & \multirow[b]{2}{*}{ Type } & \multirow[b]{2}{*}{$\mathbf{t}_{\text {Ret }}[\mathbf{s}]$} & \multirow{2}{*}{$\begin{array}{c}\text { Molecular } \\
\text { ion } \mathbf{M}^{+.} \\
(\mathrm{m} / \mathbf{z})\end{array}$} & \multirow{2}{*}{$\begin{array}{l}\text { Base } \\
\text { peak } \\
(\mathrm{m} / \mathrm{z})\end{array}$} & \multirow[b]{2}{*}{ Other ions $(m / z)$} & \multicolumn{2}{|c|}{ Molar fraction at $\mathrm{t}=\mathrm{x}$ min } \\
\hline & & & & & & $\mathbf{0}$ & 360 \\
\hline$A^{4}$ & diene & 513 & 340 & 121 & $325,305,171,106,91,69$ & 0.009 & 0.076 \\
\hline $\mathbf{C}^{4}$ & diene & 532 & 340 & 121 & $105,93,69$ & 0 & 0.016 \\
\hline$D^{4}$ & diene & 544 & 340 & 325 & $305,171,121,91,69$ & 0.001 & 0.024 \\
\hline $\mathbf{E}^{4}$ & diene & 560 & 340 & 171 & $320,305,156,91,69$ & 0.004 & 0.105 \\
\hline $\mathbf{F}^{4}$ & diene & 568 & 340 & 171 & $320,305,151,91,69$ & 0 & 0.122 \\
\hline$G^{4}$ & diene & 575 & 340 & 171 & $320,305,151,91,69$ & 0.024 & 0.607 \\
\hline $\mathbf{H}^{4}$ & diene & 587 & & 320 & $305,201,171,151,69$ & 0 & 0.015 \\
\hline $\mathbf{I}^{4}$ & diene & 603 & 343 & 343 & $305,171,121,91,69$ & 0 & 0.005 \\
\hline $\mathbf{V}^{4}$ & alcohol & 608 & & 139 & $341,171,121,69$ & 0.813 & 0.001 \\
\hline $\mathbf{W}^{4}$ & alcohol & 611 & & 139 & $340,171,121,69$ & 0.016 & 0 \\
\hline $\mathbf{X}^{4}$ & alcohol & 618 & & 121 & $139,95,69$ & 0.128 & 0.032 \\
\hline
\end{tabular}

${ }^{a}$ GC-MS (minor isomers omitted), glass capillary column $30 \mathrm{~m} / 25 \mathrm{um}$, poly(dimethylsiloxane-co5\% methylphenylsiloxane) phase, programmed temperature: 50(5)-20/120(0)-40/250.

Table 3. Composition of reaction mixture of perfluorohexyl derivatives ${ }^{\mathrm{a}}$.

\begin{tabular}{|c|c|c|c|c|c|c|c|c|c|}
\hline \multirow[b]{2}{*}{ Isomer } & \multirow[b]{2}{*}{ Type } & \multirow{2}{*}{$\begin{array}{c}\mathbf{t}_{\text {Ret }} \\
{[\mathbf{s}]}\end{array}$} & \multirow{2}{*}{$\begin{array}{c}\text { Mol. } \\
\text { ion } \mathbf{M}^{+} \text {. } \\
(m / z) \\
\end{array}$} & \multirow{2}{*}{$\begin{array}{l}\text { Base } \\
\text { peak } \\
(\mathrm{m} / \mathrm{z})\end{array}$} & \multirow[b]{2}{*}{ Other ions $(m / z)$} & \multicolumn{4}{|c|}{ Molar fraction at $t=x$ min } \\
\hline & & & & & & $\mathbf{0}^{\mathbf{b}}$ & $483^{b}$ & $0^{c}$ & $480^{c}$ \\
\hline$A^{6}$ & diene & 577 & 440 & 121 & $425,171,91,69$ & 0.011 & 0.119 & 0.025 & 0 \\
\hline $\mathbf{B}^{6}$ & diene & 581 & & 113 & $403,69,57$ & 0.015 & 0.019 & 0.025 & 0.054 \\
\hline $\mathrm{C}^{6}$ & diene & 591 & 440 & 69 & 121,93 & 0.004 & 0.013 & 0.002 & 0.002 \\
\hline$D^{6}$ & diene & 599 & 440 & 69 & $425,171,121,91$ & 0.002 & 0.018 & 0.004 & 0.007 \\
\hline$E^{6}$ & diene & 609 & 440 & 171 & $420,119,69$ & 0.005 & 0.105 & 0.012 & 0.031 \\
\hline$\left(F^{6}\right)^{d}$ & diene & 617 & 440 & 171 & $425,151,105,69$ & & & & \\
\hline$G^{6}$ & diene & 620 & 440 & 171 & $420,201,151,105,69$ & $0.048^{\mathrm{e}}$ & $0.679^{\mathrm{e}}$ & $0.108^{\mathrm{e}}$ & $0.252^{\mathrm{e}}$ \\
\hline $\mathbf{H}^{6}$ & diene & 625 & & 405 & $420,186,171,151,69$ & 0.008 & 0.016 & 0 & 0.014 \\
\hline$I^{6}$ & diene & 628 & & 69 & $\begin{array}{l}420,401,201,181, \\
151,119\end{array}$ & 0 & 0 & 0.006 & 0.536 \\
\hline$J^{6}$ & diene & 636 & & 420 & $201,171,151,69$ & 0 & 0 & 0.044 & 0.046 \\
\hline$K^{6}$ & diene & 641 & 443 & 443 & $171,121,83,69$ & 0 & 0 & 0.005 & 0.005 \\
\hline $\mathbf{V}^{6}$ & alcohol & 646 & & 139 & $440,171,121,69$ & 0.818 & 0.031 & 0.582 & 0 \\
\hline $\mathbf{W}^{6}$ & alcohol & 648 & & 139 & $440,171,121,69$ & 0.09 & 0.026 & 0.11 & 0 \\
\hline$X^{6}$ & alcohol & 655 & & 139 & $443,171,121,95,69$ & 0 & 0.005 & 0.079 & 0.051 \\
\hline$Y^{6}$ & alcohol & 658 & & 139 & $440,121,95,69$ & 0.005 & 0.005 & 0 & 0 \\
\hline
\end{tabular}

${ }^{a}$ GC-MS (minor isomers omitted), glass capillary column $30 \mathrm{~m} / 25 \mathrm{um}$, poly(dimethylsiloxane-co5\% methylphenylsiloxane) phase, programmed temperature: 50(5)-20/120(0)-40/250; ${ }^{\mathrm{b}}$ solvent benzene; ${ }^{\mathrm{c}}$ solvent chlorobenzene; ${ }^{\mathrm{d}}$ not fully separated from isomer $\mathbf{G}^{\mathbf{6}}$; ${ }^{\mathrm{e}}$ total $\mathbf{F}^{\mathbf{6}}+\mathbf{G}^{\mathbf{6}}$. 
Table 4. Composition of reaction mixture of perfluorooctyl derivatives ${ }^{\mathrm{a}}$.

\begin{tabular}{cccccl}
\hline Isomer & Type & $\mathbf{t}_{\text {Ret }[\mathbf{s}]}$ & $\begin{array}{c}\text { Molecular ion } \\
\mathbf{M}^{+\cdot}(\mathbf{m} / \mathbf{z})\end{array}$ & $\begin{array}{c}\text { Base peak } \\
(\mathbf{m} / \mathbf{z})\end{array}$ & \multicolumn{1}{c}{ Other ions $(\mathbf{m} / \mathbf{z})$} \\
\hline $\mathbf{A}^{\mathbf{8}}$ & diene & 641 & 540 & 121 & $525,171,105,91,69$ \\
$\mathbf{B}^{\mathbf{8}}$ & diene & 644 & & 113 & $121,69,57$ \\
$\mathbf{C}^{8}$ & diene & 651 & 540 & 121 & $105,91,69$ \\
$\mathbf{D}^{\mathbf{8}}$ & diene & 657 & 540 & 121 & $525,171,105,69$ \\
$\mathbf{F}^{\mathbf{8}}$ & diene & 666 & 540 & 171 & $521,156,121,105,69$ \\
$\mathbf{G}^{\mathbf{8}}$ & diene & 673 & 540 & 171 & $520,201,151,69$ \\
$\mathbf{H}^{\mathbf{8}}$ & diene & 679 & 540 & 201 & $520,501,171,151,69$ \\
$\mathbf{V}^{\mathbf{8}}$ & alcohol & 694 & & 139 & $540,121,69$ \\
$\mathbf{W}^{\mathbf{8}}$ & alcohol & 696 & & 139 & $540,121,69$ \\
$\mathbf{X}^{\mathbf{8}}$ & alcohol & 702 & & 139 & $540,121,105,95,69$ \\
$\mathbf{Y}^{\mathbf{8}}$ & alcohol & 706 & & 139 & $540,121,95,69$ \\
$\mathbf{Z}^{\mathbf{8}}$ & alcohol & 710 & & 139 & $540,157,113,95,69,56$ \\
\hline
\end{tabular}

${ }^{a}$ GC-MS (minor isomers omitted), glass capillary column $30 \mathrm{~m} / 25 \mathrm{um}$, poly(dimethylsiloxane-co5\% methylphenylsiloxane) phase, programmed temperature: 90(5)-20/120(0)-40/250.

\subsubsection{Kinetic Observations}

Reaction with $\mathrm{P}_{2} \mathrm{O}_{5}$ at $80{ }^{\circ} \mathrm{C}$ in benzene and the more polar chlorobenzene (perfluorohexyl derivatives only) was chosen for the formal kinetic evaluation of the dehydration of (perfluoroalkyl)tetramethylcyclopentenols. The chromatographic separation conditions were adjusted to maximum possible separation of individual isomers (see Tables 2-4). The dehydration of the sum of alcohols to the sum of dienes formed the input of the kinetics treatment.

Figure 3 shows the concentration changes of both alcohols and dienes with reaction time. The experimental data were fitted obtaining thus the estimates of rate constants $k$ and reaction orders $n$ together with the estimated standard deviation s.d. of the fitting. Our own program for fitting formal kinetics was based on the parametric nonlinear optimization method designed by Marquardt [32].

Figure 3. Dehydration of (perfluorobutyl) tetramethylcyclopentenols $\left(\mathrm{P}_{2} \mathrm{O}_{5}\right.$, benzene, $\left.80{ }^{\circ} \mathrm{C}\right) \mathrm{k}=0.071, \mathrm{n}=2$, s.d. $=0.017$; points-experimental concentrations, lines-fitted functions; solid line-dienes total, dashed line-alcohols total.

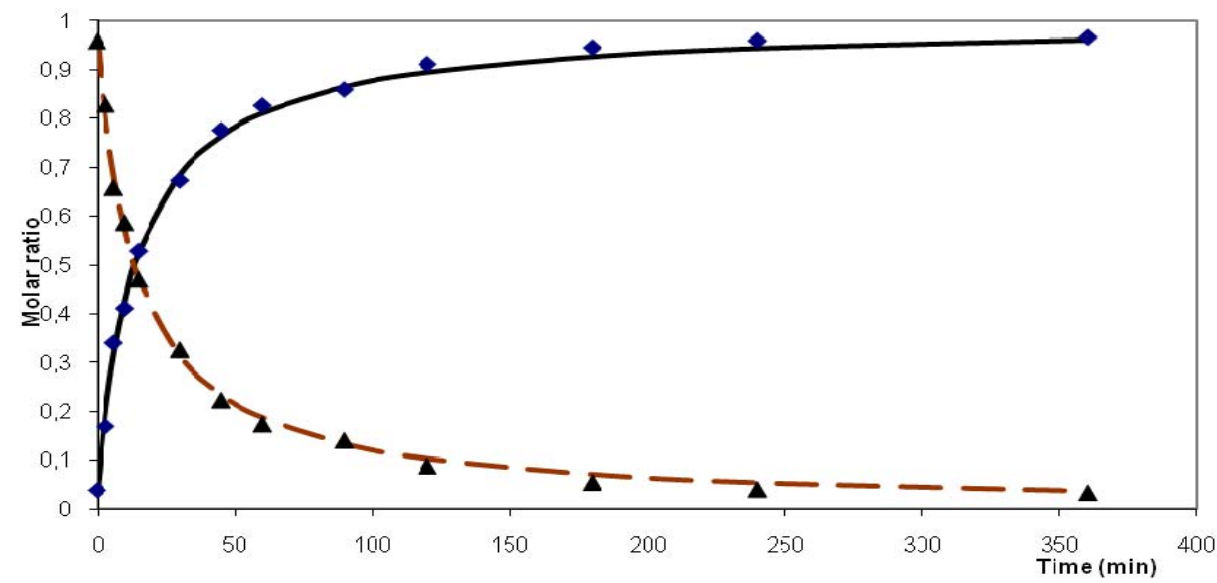


The decrease of an individual alcohol (or group of alcohols) concentration and increase of an individual diene (or a small group of dienes) concentration with time was taken as a basis for assignment of particular dienes being products of particular alcohols dehydration. Dehydration of both perfluorobutyl and perfluorohexyl substituted alcohols in benzene apparently follows a second order with respect to the starting alcohol. Dehydration of the perfluorohexyl substituted alcohol in chlorobenzene followed a different course and the reaction was better described as formally being of zeroth order with an induction period of 5 min (Figure 4).

Figure 4. Dehydration of (perfluorohexyl) tetramethylcyclopentenols $\left(\mathrm{P}_{2} \mathrm{O}_{5}\right.$, chlorobenzene, $80^{\circ} \mathrm{C}$ ) individual reaction of alcohol isomer $\mathbf{V}^{\mathbf{6}}$ into the dienes isomers $\mathbf{F}^{\mathbf{6}}+\mathbf{G}^{\mathbf{6}}+\mathbf{E}^{\mathbf{6}} \mathrm{k}=0.023, \mathrm{n}=0$, s.d. $=0.023$, induction period 5min; points-experimental concentrations, lines-fitted functions; solid line-dienes $\mathbf{F}^{\mathbf{6}}+\mathbf{G}^{\mathbf{6}}+\mathbf{E}^{\mathbf{6}}$, dashed line-alcohol $\mathbf{V}^{\mathbf{6}}$.

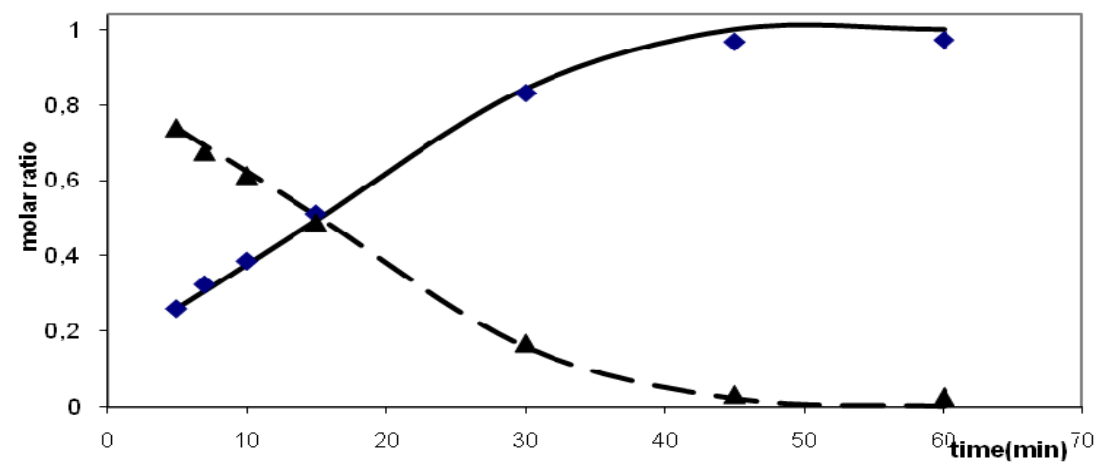

Such kinetics can often be found in reaction systems with mass transfer of one of the reactants through phase boundary as a rate limiting step (Table 5). Formation of microemulsions was suggested in apparent solutions of fluorous compounds in organic solvents.

Table 5. Kinetic approximation of dehydration of (perfluoroalkyl)cyclopentenols.

\begin{tabular}{|c|c|c|c|c|c|c|c|}
\hline Substrate & Solvent & $\begin{array}{l}\text { Temp. } \\
\left({ }^{\circ} \mathrm{C}\right)\end{array}$ & $\begin{array}{c}\text { Rate } \\
\text { constant }^{\mathrm{a}}\end{array}$ & $\begin{array}{c}\text { Reaction } \\
\text { order }\end{array}$ & $\begin{array}{l}\text { Standard } \\
\text { deviation }\end{array}$ & $\begin{array}{c}\text { Time }_{50 \%}{ }^{\mathrm{c}} \\
{[\mathrm{min}]}\end{array}$ & $\begin{array}{c}\text { Time }_{90} \%{ }^{\mathrm{c}} \\
{[\mathrm{min}]}\end{array}$ \\
\hline CPT-C6F13-OH & benzene & 80 & & & & & \\
\hline total reaction & & & 0.022 & 2 & 0.042 & 36 & 385 \\
\hline $\begin{array}{l}\text { individual reaction: } \\
\mathbf{V}^{\mathbf{6}} \text { to } \mathbf{F}^{\mathbf{6}}+\mathbf{G}^{\mathbf{6}}+\mathbf{E}^{\mathbf{6}}\end{array}$ & & & 0.036 & 2 & 0.032 & & \\
\hline СРТ-С6F13-OH & Cl-benzene & 80 & & & & & \\
\hline total reaction & & & 0.016 & 0 & 0.085 & 15 & 38 \\
\hline $\begin{array}{l}\text { individual reaction: } \\
\mathbf{V}^{\mathbf{6}} \text { to } \mathbf{F}^{\mathbf{6}}+\mathbf{G}^{\mathbf{6}}+\mathbf{E}^{\mathbf{6}}\end{array}$ & & & 0.023 & $0^{\mathrm{b}}$ & 0.023 & & \\
\hline CPT-C4F9-OH & benzene & 80 & & & & & \\
\hline total reaction & & & 0.071 & 2 & 0.017 & 14 & 114 \\
\hline individual reaction: & & & & & & & \\
\hline $\mathbf{V}^{4}+\mathbf{X}^{4}$ to $\mathbf{F}^{4}+\mathbf{G}^{4}$ & & & 0.056 & 2 & 0.086 & & \\
\hline
\end{tabular}


The analysis of time dependence of individual perfluorobutyl substituted diene isomers revealed that the major alcohol isomer ( $81 \%$ in the starting mixture, denoted $\left.\mathbf{V}^{\mathbf{4}}\right)$ was transformed into a diene mixture comprising major diene isomers $\mathbf{F}^{4}$ and $\mathbf{G}^{4}$. The second most abundant alcohol $\mathbf{X}^{\mathbf{4}}(13 \%$ in the starting mixture) seemed to be the main source for diene $\mathbf{A}^{\mathbf{4}}$; both compounds were characterized by the presence of an ion with $\mathrm{m} / \mathrm{z}=121$ in the mass spectra. The rate of formation of diene isomer $\mathbf{E}^{\mathbf{4}}$ exceeded the overall rate of alcohol dehydration, especially above $90 \%$ conversion, which is evidence for diene $\mathbf{E}^{4}$ being formed by the isomerization of other diene isomers.

Figure 5. Dehydration of (perfluorohexyl)tetramethylcyclopentenols $\left(\mathrm{P}_{2} \mathrm{O}_{5}\right.$, chlorobenzene, $80{ }^{\circ} \mathrm{C}$ ). Isomeration of (perfluorohexyl)tetramethylcyclopentadienes $\mathbf{F}^{\mathbf{6}}+\mathbf{G}^{\mathbf{6}}$ into isomer $\mathbf{I}^{\mathbf{6}}$ solid line-generation of diene isomers $\mathbf{F}^{\mathbf{6}}+\mathbf{G}^{\mathbf{6}}$, dashed line-generation of diene isomer $\mathbf{I}^{\mathbf{6}}$.

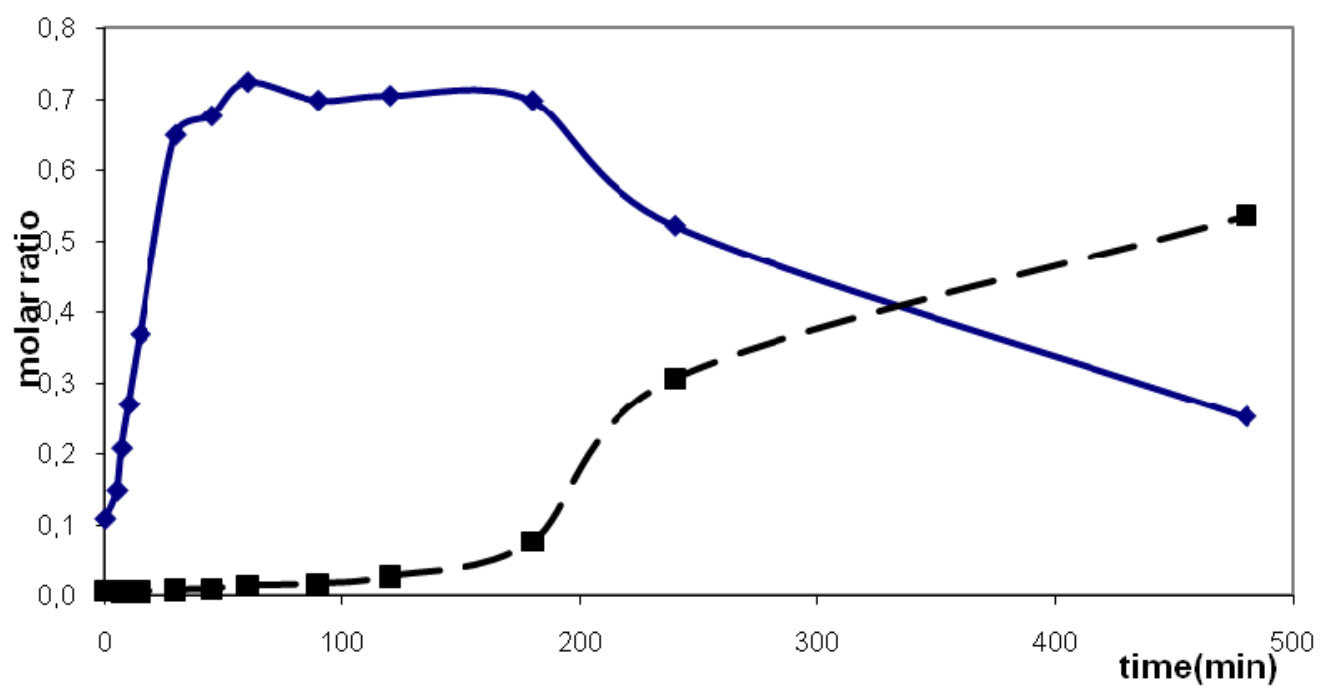

Dehydration of perfluorohexyl substituted alcohol isomers involved the reaction of isomer $\mathbf{V}^{\mathbf{6}}$ mainly ( $82 \%$ in the starting mixture) giving dienes $\mathbf{F}^{\mathbf{6}}$ and $\mathbf{G}^{\mathbf{6}}$ together with isomer $\mathbf{E}^{\mathbf{6}}$. The different rate of formation of isomer $\mathbf{A}^{\mathbf{6}}$ supports its formation by isomerization from the other dienes.

The course of dehydration of $\mathrm{C}_{6}$ alcohol in chlorobenzene differed somewhat from that found in benzene. In chlorobenzene, the yield of the major product, i.e. the dienes $\mathbf{F}^{\mathbf{6}}+\mathbf{G}^{\mathbf{6}}$ reached a maximum at $180 \mathrm{~min}$ reaction time, at longer times the dienes seemed to isomerize to diene $\mathbf{I}^{6}$ (Figure 5). Similarly, the concentration of isomer $\mathbf{A}^{\mathbf{6}}$ went through a maximum in the course of the reaction, the amount of $\mathbf{A}^{\mathbf{6}}$ being outside detection limit already at 240 min reaction time.

\section{Experimental}

\subsection{General}

Manipulations with Grignard reagents were carried out under an argon atmosphere. Perfluorohexyl and perfluorooctyl iodide (both ABCR), perfluorobutyl iodide, phosphorus oxychloride and chlorobenzene, (all Aldrich), bromobenzene (Latwopalne) and the solvents benzene, toluene, and pyridine (all Lachema) were commercial products used without further purification. (Perfluoroalkyl)- 
tetramethylcyclopentenols (mixtures of isomers) were prepared according to the literature method [19]. Preliminary dehydration experiments were analyzed by gas chromatography on a Hewlett Packard 5890 instrument using nitrogen carrier gas with HP DB-5 column $(30 \mathrm{~m} \times 0.25 \mathrm{~mm}, 5 \%$ phenylmethylsilicone stationary phase). Temperature program: $100{ }^{\circ} \mathrm{C}(5 \mathrm{~min})-5^{\circ} \mathrm{C} / \mathrm{min}-280{ }^{\circ} \mathrm{C}$ final. ${ }^{13} \mathrm{C}\left\{{ }^{1} \mathrm{H}\right\}$ NMR spectra were measured on a Varian Mercury 300 spectrometer at $75.44 \mathrm{MHz}$ in or $\mathrm{CDCl}_{3}$ solutions at $25^{\circ} \mathrm{C}$. Chemical shifts $(\delta)$ are reported in ppm relative to TMS, referenced to the solvent peak.

\subsection{Screening Dehydration Experiments-General Procedure}

The experiments were carried out with $3 \mathrm{mmol}$ of the mixture of (perfluoroalkyl) tetramethyl-cyclopentenols in $10 \mathrm{~mL}$ of solvent unless stated otherwise, and progress of reactions was followed by gas chromatography at 1-2 $\mathrm{h}$ intervals. The reaction mixture was treated with ice or ice-cooled water, organic layer separated, aqueous layer extracted with ether $(3 \times 10 \mathrm{~mL})$, the combined organic leyers were washed with saturated $\mathrm{NaHCO}_{3}$ solution $(20 \mathrm{~mL})$ and with saturated $\mathrm{NaCl}$ solution $(20 \mathrm{~mL})$ then dried overnight with $\mathrm{MgSO}_{4}$. The mixtures were then distilled, solvents were removed under atmospheric pressure and products collected in vacuum: fraction boiling at $65-67{ }^{\circ} \mathrm{C} / 5$ Torr for perfluorobutyl, $83-85^{\circ} \mathrm{C} / 4$ Torr for perfluorohexyl, and $102-103{ }^{\circ} \mathrm{C} / 3$ Torr for perfluoorooctyl derivatives.

\subsection{Dehydration with $\mathrm{POCl}_{3}$}

Phosphorus oxychloride $(1.6 \mathrm{~mL}, 17 \mathrm{mmol})$ was cooled to $-5{ }^{\circ} \mathrm{C}$, pyridine $(6 \mathrm{~mL})$ added and the solution of (perfluorobutyl)tetramethylcyclopentenols $(1.074 \mathrm{~g}, 3 \mathrm{mmol})$ in pyridine $(11 \mathrm{~mL})$ slowly dropped to the mixture under stirring and cooling to $0{ }^{\circ} \mathrm{C}$. The reaction mixture was then heated at $90{ }^{\circ} \mathrm{C}$ for $4 \mathrm{~h}$, then worked up as mentioned above. The product $(0.95 \mathrm{~g})$ contained $59 \%$ of dienes (GC yield $55 \%$ ), $10 \%$ of unreacted alcohols and $28 \%$ of unidentified by-products.

\subsection{Dehydration with $\mathrm{BF}_{3} \cdot \mathrm{Et}_{2} \mathrm{O}$}

Boiling of (perfluorobutyl)tetramethylcyclopentenols $(1.074 \mathrm{~g}, 3 \mathrm{mmol})$ with equimolar amount of $\mathrm{BF}_{3} \cdot \mathrm{OEt}_{2}(0.4 \mathrm{~mL})$ in diethyl ether $(10 \mathrm{~mL})$ gave after $9 \mathrm{~h} 1.091 \mathrm{~g}$ of the product containing $77 \%$ of dienes (GC yield 82\%), 14\% of unreacted alcohols and $9 \%$ of unidentified by-products.

\subsection{Dehydration with $\mathrm{SOCl}_{2}$}

Boiling of (perfluorobutyl)tetramethylcyclopentenols (1.074 g, $3 \mathrm{mmol})$ with equimolar amount of thionyl chloride $(0.22 \mathrm{~mL})$ in benzene $(10 \mathrm{~mL})$ gave after $10 \mathrm{~h} 0.923 \mathrm{~g}$ of the product containing $91 \%$ of dienes (GC yield $82 \%$ ), 2\% of unreacted alcohols and $7 \%$ of unidentified by-products.

\subsection{Dehydration with $\mathrm{PCl}_{5}$}

Boiling of (perfluorobutyl)tetramethylcyclopentenols $(1.074 \mathrm{~g}, 3 \mathrm{mmol})$ with half of the equimolar amount of phosphorus pentachloride $(0.32 \mathrm{~g}$ in $0.97 \mathrm{~mL}$ of pyridine $)$ in benzene $(10 \mathrm{~mL})$ gave after $10 \mathrm{~h}$ 
$0.930 \mathrm{~g}$ of the product containing $44 \%$ of dienes, $53 \%$ of unreacted alcohols and $3 \%$ of unidentified by-products.

Using equimolar amount of phosphorus pentachloride afforded $0.915 \mathrm{~g}$ of the product containing $90 \%$ of dienes (GC yield $81 \%$ ), no unreacted alcohols and $10 \%$ of unidentified by-products.

\subsection{Dehydration with $\mathrm{P}_{2} \mathrm{O}_{5}$ in Benzene}

(Perfluorobutyl) tetramethylcyclopentenols $(1.074 \mathrm{~g}, 3 \mathrm{mmol})$ were added to the suspension of $\mathrm{P}_{2} \mathrm{O}_{5}$ $(0.4 \mathrm{~g}, 2.8 \mathrm{mmol})$ in benzene $(10 \mathrm{~mL})$ with stirring. The reaction mixture was then heated at $90{ }^{\circ} \mathrm{C}$ for $9 \mathrm{~h}$, then worked up as mentioned above. The product $(0.92 \mathrm{~g})$ contained $89 \%$ of dienes (GC yield $80 \%$ ), $6 \%$ of unreacted alcohols and $5 \%$ of unidentified by-products.

\subsection{Dehydration with $\mathrm{P}_{2} \mathrm{O}_{5}$ in Toluene (Microwave Heating)}

(Perfluorobutyl) tetramethylcyclopentenols $(1.074 \mathrm{~g}, 3 \mathrm{mmol})$ were added to the suspension of $\mathrm{P}_{2} \mathrm{O}_{5}$ $(0.25 \mathrm{~g}, 1.75 \mathrm{mmol})$ in toluene $(10 \mathrm{~mL})$ with stirring. The reaction mixture was then refluxed in a microwave reactor at $25 \%$ of the full power (i.e. $150 \mathrm{~W})$ for $7 \mathrm{~h}$. The product $(0.96 \mathrm{~g})$ contained $86 \%$ of dienes (GC yield 81\%), 5\% of unreacted alcohols and $9 \%$ of unidentified by-products.

\subsection{Dehydration with $\mathrm{P}_{2} \mathrm{O}_{5}$ in the Presence of $\mathrm{BF}_{3} \cdot \mathrm{Et}_{2} \mathrm{O}$ at $40{ }^{\circ} \mathrm{C}$}

The mixture of phosphorus pentoxide $(0.852 \mathrm{~g}, 6 \mathrm{mmol})$ and (perfluorobutyl) tetramethylcyclopentenols $(1.074 \mathrm{~g}, 3 \mathrm{mmol})$ in diethyl ether $(10 \mathrm{~mL})$ was cooled to $-5{ }^{\circ} \mathrm{C}$ and $\mathrm{BF}_{3} \cdot \mathrm{Et}_{2} \mathrm{O}(40 \mu \mathrm{L}$, $0.045 \mathrm{~g}, 0.317 \mathrm{mmol}$ ) added with stirring. The reaction mixture was then heated at $42{ }^{\circ} \mathrm{C}$ for $8 \mathrm{~h}$, then worked up as mentioned above. The product $(0.921 \mathrm{~g})$ contained $83 \%$ of dienes (GC yield $75 \%$ ), 14\% of unreacted alcohols and $3 \%$ of unidentified by-products.

\subsection{Dehydration with $\mathrm{P}_{2} \mathrm{O}_{5}$ in the Presence of $\mathrm{BF}_{3} \cdot \mathrm{Et}_{2} \mathrm{O}$ at Room Temperature}

The same mixture as prepared above was stirred at room temperature for 7 days. The product $(0.819 \mathrm{~g})$ contained $86 \%$ of dienes (GC yield $69 \%$ ), $10 \%$ of unreacted alcohols and $4 \%$ of unidentified by-products.

\subsection{Kinetics}

Samples of reaction mixtures were filtered through $\mathrm{K}_{2} \mathrm{CO}_{3}$ to remove $\mathrm{P}_{2} \mathrm{O}_{5}$ and diluted by diethyl ether. GC-MS analysis was run on a Varian 3500 gas chromatograph equipped with a glass capillary column (30m length and $0.025 \mathrm{~mm}$ diameter) coated with poly(dimethylsiloxane-co-5\% methylphenylsiloxane) phase (temperature program $50-250{ }^{\circ} \mathrm{C}$ ) connected to a Finnigan Mat mass ITD detector working at $70 \mathrm{eV}$. The acquisition range was 45 to 400,500 or 600 a.m.u., according to the length of perfluoroalkyl chain. In the course of dehydration reaction to the mixture of isomeric (perfluoroalkyl)tetramethylcyclopentadienes, changes of the isomer composition of starting alcohols mixture were also monitored. Unfortunately, some of the isomers of starting alcohols as well as isomers of dienes were not always separable. 


\subsection{NMR Characterization of Identified Main Products}

Isomer 9

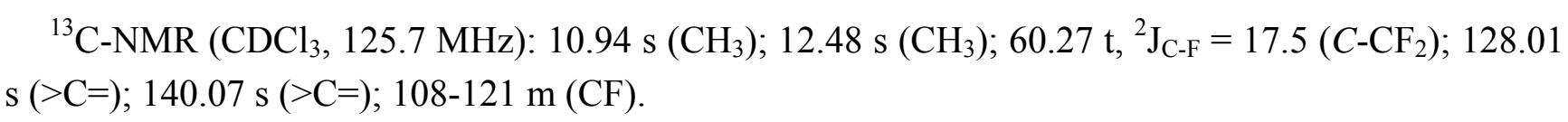

Isomer $\mathbf{1 0}$

${ }^{13} \mathrm{C}-\mathrm{NMR}\left(\mathrm{CDCl}_{3}, 125.7 \mathrm{MHz}\right): 10.36 \mathrm{~s}\left(\mathrm{CH}_{3}\right) ; 11.67 \mathrm{~s}\left(\mathrm{CH}_{3}\right) ; 12.74$ bs $\left(\mathrm{CH}_{3}\right) ; 14.00$ bs $\left(\mathrm{CH}_{3}\right)$; $50.06 \mathrm{~s}(\mathrm{CH}) ; 127.49 \mathrm{t},{ }^{2} \mathrm{~J}_{\mathrm{C}-\mathrm{F}}=23.4\left(=\mathrm{C}-\mathrm{CF}_{2}\right) ; 134.28 \mathrm{~d},{ }^{3} \mathrm{~J}_{\mathrm{C}-\mathrm{F}}=1.8(>\mathrm{C}=) ; 146.49 \mathrm{~s}(>\mathrm{C}=) ; 150.83 \mathrm{bs}$ $(>\mathrm{C}=) ; 108-121 \mathrm{~m}(\mathrm{CF})$.

Isomers 12/13

${ }^{13} \mathrm{C}-\mathrm{NMR}\left(\mathrm{CDCl}_{3}, 125.7 \mathrm{MHz}\right): 11.11 \mathrm{~s}\left(\mathrm{CH}_{3}\right) ; 20.39 \mathrm{~s}\left(\mathrm{CH}_{3}\right) ; 20.49 \mathrm{~s}\left(\mathrm{CH}_{3}\right) ; 45.73 \mathrm{~s}(\mathrm{CH}) ; 47.38 \mathrm{~s}$ $(\mathrm{CH}) ; 106.31 \mathrm{~s}\left(=\mathrm{CH}_{2}\right) ; 145.54 \mathrm{bs}(>\mathrm{C}=) ; 159.04 \mathrm{~s}(>\mathrm{C}=) ; 108-121 \mathrm{~m}(\mathrm{CF})$.

\section{Conclusions}

Dehydration of (perfluoroalkyl) tetramethylcyclopentenols gave a broad spectrum of products which were isomers of either endo,endo- or endo,exo-cyclopentadienes. The reagent of choice for the dehydration was phosphorus pentoxide in benzene with which the yield was improved up to $89 \%$ of dienes in comparison with the literature. Structures could be assigned to three main products of the dehydration showing that the endo,endo-isomers prevail. Due to complexity of reaction mixture, formal kinetic evaluation of the dehydration reaction was carried out with sum of alcohols on one side of the reaction and sum of dienes on the other side, some products were followed independently, however. In benzene, perfluorobutyl and perfluorohexyl substituted alcohols followed the second order dehydration kinetics while in more polar chlorobenzene perfluorohexyl substituted alcohol followed the zeroth order reaction with an induction period suggesting mass transfer limitations. At higher conversions some of the products isomerized, the reaction being more pronounced in chlorobenzene.

\section{Acknowledgements}

The support of grant agencies (Grant Agency of the Academy of Sciences, A4072203; Ministry of Education, Youth and Sport of the Czech Republic, LC06070) is gratefully acknowledged.

\section{References and Notes}

1. Handbook of Fluorous Chemistry; Gladysz, J.A., Curran, D.P., Horváth, I.T., Eds.; Wiley-VCH: Weinheim, Germany, 2004.

2. Horváth, I.T.; Rábai, J. Facile catalyst separation without water: Fluorous biphase hydroformylation of olefins. Science 1994, 266, 72-75.

3. Horváth, I.T. Fluorous biphase chemistry. Acc. Chem. Res. 1998, 31, 641-650. 
4. Betzemeier, B.; Knochel, P. Perfluorinated solvents - a novel reaction medium in organic chemistry. Top. Curr. Chem. 1999, 206, 61-78.

5. Barthel-Rosa L.P.; Gladysz J.A. Chemistry in fluorous media: A user's guide to practical considerations in the application of fluorous catalysis and reagents. Coord. Chem. Rev. 1999, 190, 587-605.

6. Vincent, J.-M.; Rabion, A.; Yachandra, V.K.; Fish, R.H. Fluorous biphasic catalysis: Complexation of 1,4,7-[ $\left[\mathrm{C}_{8} \mathrm{~F}_{17}\left(\mathrm{CH}_{2}\right)_{3}\right]_{3}$-1,4,7-triazacyclononane with $\left[\mathrm{M}\left(\mathrm{C}_{8} \mathrm{~F}_{17}\left(\mathrm{CH}_{2}\right)_{2} \mathrm{CO}_{2}\right)_{2}\right](\mathrm{M}=$ $\mathrm{Mn}, \mathrm{Co}$ to provide perfluoroheprane-soluble catalysts for alkane and alkene functionalization in the presence of t-BuOOH and $\mathrm{O}_{2}$. Angew. Chem. Int. Ed. 1997, 36, 2346-2349.

7. Pozzi, G.; Mihali, V.; Foschi, F.; Penso, M.; Quici, S.; Fish, R.H. 3,5-Bis(nperfluorooctyl)benzyltriethylammonium bromide (F-TEBA): An efficient, easily recoverable fluorous catalyst for solid-liquid PTC reactions. Adv. Synth. Catal. 2009, 351, 3072-3076.

8. Pozzi, G.; Shepperson, I. Fluorous chiral ligands for novel catalytic systems. Coord. Chem. Rev. 2003, 242, 115-124.

9. Hughes, R.P.; Trujillo, H.A. Selective solubility of organometallic complexes in saturated fluorocarbons. Synthesis of cyclopentadienyl ligands with fluorinated ponytails. Organometallics 1996, 15, 286-294.

10. Bříza, T.; Kvíčala, J.; Mysík, P.; Paleta, O.; Čermák, J. 2-(Perfluoroalkyl)ethyl triflates, building blocks for the synthesis of bis(polyfluoroalkylated) cyclopentadienes. Synlett 2001, 2001, 685-687.

11. Bříza, T.; Kvíčala, J.; Paleta, O.; Čermák, J. Preparation of bis(polyfluoroalkyl)cyclopentadienes, new highly fluorophilic ligands for fluorous biphase catalysis. Tetrahedron 2002, 58, 3841-3846.

12. Kvíčala, J.; Bříza, T.; Paleta, O.; Auerová, K.; Čermák, J. Synthesis, Fluorophilicities and regioisomer composition of ferrocenes and rhodium complexes based on bis(polyfluoroalkylated) cyclopentadienes. Tetrahedron 2002, 58, 3847-3854.

13. Dinh, L.V.; Gladysz, J.A. Convenient syntheses of "heavy fluorous" cyclopentadienes and cyclopentadienyl complexes with three to five ponytails. Chem. Commun. 2004, 998-999.

14. Dinh, L.V.; Gladysz, J.A. "Heavy fluorus" cyclopentadienes and cyclopentadienyl complexes with three to five ponytails: Facile syntheses from polybromocyclopentadienyl complexes, phase properties, and electronic effects. Chem. Eur. J. 2005, 11, 7211-7222.

15. Čermák, J.; Št’astná, L.; Sýkora, J.; Císařová, I.; Kvíčala, J. Trimethylsilylcyclopentadienes with polyfluorinated ponytails and mono- and bis( $\eta 5$-cyclopentadienyl) titanium(IV) complexes derived from them. Organometallics 2004, 23, 2850-2854.

16. Merle, P.G.; Chéron, V.; Hagen, H.; Lutz, M.; Spek, A.L.; Deelman, B.-J.; van Koten, G. Fluorous zirconocene(IV) complexes and their olefin polymerization activity in toluene and fluorous biphasic solvent systems. Organometallics 2005, 24, 1620-1630.

17. Červenková Št’astná, L.; Auerová, K.; Kvíčala, J.; Čermák, J. Fluorophilic properties of (perfluorooctyl)ethyldimethylsilyl substituted and tetramethyl(perfluoroalkyl) substituted cyclopentadienes and their Ti(IV), Rh(III), and Rh(I) complexes. J. Organomet. Chem. 2007, 692, 1974-1982.

18. Červenková Št’astná, L.; Čermák, J.; Cuř́nová, P.; Sýkora, J. Synthesis and fluxional behavior of new "heavy fluorous" cyclopentadienes. J. Organomet. Chem. 2010, 695, 537-545. 
19. Čermák, J.; Auerová, K.; Nguyen, H.T.T.; Blechta, V.; Vojtíšek, P.; Kvíčala, J. Synthesis of rhodium complexes with novel perfluoroalkyl substituted cyclopentadienyl ligands. Collect. Czech. Chem. Commun. 2001, 66, 382-396.

20. Čermák, J.; Žádný, J.; Krupková, A.; Lopatová, K.; Vlachová, A.; Nguyen Thi, T.H.; Šauliová, J.; Sýkora, J.; Císařová, I. Tetramethyl(perfluoroalkyl)cyclopentadienyl rhodium(III) complexes containing phosphorus and nitrogen monodentate donors. Crystal structure of $\left[\left(\eta^{5}-\mathrm{C}_{5} \mathrm{Me}_{4} \mathrm{C}_{4} \mathrm{~F}_{9}\right) \mathrm{Rh}\left(\mathrm{PPr}_{3}{ }_{3}\right) \mathrm{Cl}_{2}\right]$. J. Organomet. Chem. 2007, 692, 1557-1570.

21. Čermák, J.; Krupková, A.; Auerová, K.; Zamrzla, M.; Nguyen Thi, T.H.; Vojtíšek, P.; Císařová, I. Tetramethyl(perfluoroalkyl)cyclopentadienyl rhodium(I) complexes with ethylene or diene ligands. Crystal structure of $\left[\left(\eta^{5}-\mathrm{C}_{5} \mathrm{Me}_{4} \mathrm{C}_{6} \mathrm{~F}_{13}\right) \mathrm{Rh}(\mathrm{CO})_{2}\right]$. J. Organomet. Chem. 2010, 695, 375-381.

22. Gassman, P.G.; Mickelson, J.W.; Sowa, J.R., Jr. 1,2,3,4-Tetramethyl-5-(trifluoromethyl)cyclopentadiene: A unique ligand with the steric properties of pentamethylcyclopentadienide and the electronic properties of cyclopentadienide. J. Am. Chem. Soc. 1992, 114, 6942-6944.

23. Marken, F.; Marx, H.W.; Englert, U. Crystal-structure of twinned $\left(\eta^{5}-\mathrm{C}_{5}\left(\mathrm{CH}_{3}\right)_{4} \mathrm{CF}_{3}\right)\left(\eta^{5}-\right.$ $\left.\mathrm{C}_{5}\left(\mathrm{CH}_{3}\right)_{5}\right) \mathrm{Ru}$. Struct. Chem. 1994, 5, 177-181.

24. Gassman, P.G.; Sowa, J.R., Jr.; Hill, M.G.; Mann, K.R. Electrochemical studies of organometallic complexes with tetra-n-butylammonium tetrakis[3,5-bis(trifluoromethyl)phenyl]borate as the electrolyte. X-ray crystal structure of $\left[\mathrm{C}_{5}\left(\mathrm{CF}_{3}\right)\left(\mathrm{CH}_{3}\right)_{4}\right] \mathrm{Fe}\left(\mathrm{C}_{5} \mathrm{H}_{5}\right)$. Organometallics 1995, 14, 4879-4885.

25. Baschky, M.C.; Sowa, J.R., Jr.; Gassman, P.G.; Kass, S.R. Gas-phase generation of trifluoromethyl cyclopentadienides. J. Chem. Soc. Perkin Trans. 2 1996, 213-215.

26. Barthel-Rosa, L.P.; Sowa, J.R., Jr.; Gassman, P.G.; Fischer, J.; McCarty, B.M.; Goldsmith, S.L.; Gibson, M.T.; Nelson, J.H. Syntheses, properties, and X-ray crystal structures of iron and ruthenium compounds with the $\eta^{5}-\mathrm{C}_{5} \mathrm{Me}_{4} \mathrm{CF}_{3}$ ligand. Compounds of the type $\left[\left(\eta^{5}-\mathrm{C}_{5} \mathrm{Me}_{4} \mathrm{CF}_{3}\right) \mathrm{M}(\mu-\mathrm{CO})(\mathrm{CO})\right]_{2}(\mathrm{M}=\mathrm{Fe}, \mathrm{Ru})$. Organometallics 1997, 16, 1595-1603.

27. Gusev, O.V.; Ievlev, M.A.; Lyssenko, K.A.; Petrovskii, P.V.; Ustynyuk, N.A.; Maitlis, P.M. Synthesis and properties of the dichloro[tetramethyl(trifluoromethyl)cyclopentadienyl]ruthenium dimer: X-ray structure of $\left[\mathrm{M}_{2}\left(\eta^{5}-\mathrm{C}_{5} \mathrm{Me}_{4} \mathrm{CF}_{3}\right)_{2} \mathrm{Cl}_{2}(\mu-\mathrm{Cl})_{2}\right](\mathrm{M}=\mathrm{Ru}, \mathrm{Rh})$. Inorg. Chim. Acta 1998, 280, 249-256.

28. Gusev, O.V.; Peganova, T.A.; Ievlev, M.A.; Kropotova, A.G.; Lyssenko, K.A.; Petrovskii, P.V.; Oprunenko, Y.F.; Ustynyuk, N.A. Synthesis of platinum complexes with $\eta^{4}-\mathrm{C}_{5} \mathrm{Me}_{4}\left(\mathrm{CF}_{3}\right) \mathrm{H}$ ligand. $\mathrm{X}$-ray structure of $\left[\mathrm{Pt}\left(\eta^{4}-\mathrm{C}_{5} \mathrm{Me}_{4} \mathrm{H}_{2}\right) \mathrm{Cl}_{2}\right]$ and $\left[\mathrm{Pt}\left\{\eta^{4}-\mathrm{C}_{5} \mathrm{Me}_{4}\left(\mathrm{CF}_{3}\right) \mathrm{H}\right\}\left(\eta^{5}-\mathrm{C}_{5} \mathrm{H}_{5}\right)\right] \mathrm{PF}_{6}$. J. Organomet. Chem. 2001, 622, 221-227.

29. Hughes, R.P.; Kowalski, A.S.; Lomprey, J.R. Preparation of the 1,2-di-tert-butylcyclopentadienyl anion and a transition metal derivative. Crystal structure of 1,1',2,2'-tetra-tert-butylferrocene. Organometallics 1994, 13, 2691-2695.

30. Mellor, J.M.; El-Sagheer, A.H.; Salem, E.E.-D.M. A synthesis of trifluoromethyl-substituted naphthalenes. Tetrahedron Lett. 2000, 41, 7383-7386.

31. Mellor, J.M.; El-Sagheer, A.H.; El-Tamany, E.S.H.; Metwally, R.N. Synthesis of trifluoromethylnaphthalenes. Tetrahedron 2000, 56, 10067-10074. 
32. Marquardt, D.W. An algorithm for least-squares estimation of nonlinear parameters. J. Soc. Industr. Appl. Math. 1963, 11, 431-441.

Sample Availability: Samples of the compounds 9, 10 and 12/13 are available from the authors.

(C) 2011 by the authors; licensee MDPI, Basel, Switzerland. This article is an open access article distributed under the terms and conditions of the Creative Commons Attribution license (http://creativecommons.org/licenses/by/3.0/). 